\title{
Optimization of Concession Period for Public Private Partnership Toll Roads
}

\author{
Ke Feng', Shouqing Wang ${ }^{2}$, Chunlin $\mathrm{Wu}^{3}$, Guangtao $\mathrm{Xia}^{2}$, Wangyin $\mathrm{Hu}^{2}$ \\ ${ }^{1}$ Beijing University of Civil Engineering and Architecture \\ Xicheng District, 100044, Beijing, China \\ E-mail.fengke@bucea.edu.cn \\ ${ }^{2}$ Tsinghua University \\ Haidian District, 100084, Beijing, China \\ E-mail.sqwang@tsinghua.edu.cn,xiagt.12@sem.tsinghua.edu.cn,huwy14@mails.tsinghua.edu.cn \\ ${ }^{3}$ Beihang University \\ Haidian District, 100191, Beijing, China \\ E-mail.wuchunlin@buaa.edu.cn \\ cross $^{\text {ref }}$ http://dx.doi.org/10.5755/j01.ee.30.1.19215
}

\begin{abstract}
In the past decades, public private partnership (PPP) has been widely used as an effective approach to stimulating private investment and improving supplies for public services. The optimization of the concession period is very critical for the successful implementation of PPP projects. This paper takes decision making activities of the concession period as a bargaining game process between public and private sectors, and presents a mathematical model to calculate the optimal concession period under a series of assumptions. Backward induction is applied to solve this optimization problem. Finally, numerical simulation is used to further verify the model and analyze the influence of different factors on the optimal concession period. The results indicate that the optimal toll rate should be determined based on the average level of service provided. Factors such as the risk interest rate, initial investment, reservation utility are positively correlated with the optimal concession period, while the private equity ratio and the toll rate are negatively correlated with it. The current study is a useful supplement to previous research works as it incorporates the influence of public equity and time value of money into the construction of model. Moreover, it can act as a helpful reference for both public and private sectors in negotiations concerning related issues.
\end{abstract}

Keywords: Optimization; Concession Period; Public Private Partnership; Toll Roads; Numerical Analysis.

\section{Introduction}

Access to transportation has been proved to be an important driving force for economic prosperity (Banerjee $e t$ al., 2012; Canning \& Fay, 1993). To fill the gap between the shrinking public fiscal budgets and the increasing demand for public transportation, public private partnership (PPP) has been introduced and widely applied in many developing countries (Kappeler \& Nemoz, 2010; Ke et al., 2010). In a PPP project, the public sector grants a concession to a private sector. During the concession period, the private sector would be in charge of financing, building and operating the project, and will get reimbursed by collecting user payments (Tang et al., 2010; Osborne, 2002). Sometimes, the public sector offers fiscal subsidy or public equity in order to lessen the financing cost of the project (Skietrys et al., 2008).

The determination of concession period lies in a critical position for the successful implementation of PPP projects (Zhang \& AbouRizk, 2006). The private sector may prefer an extended concession period in order to reap more revenue. On the contrary, the public sector would limit the maximum length of concession period to protect the public's interest. Thus, the determination of an appropriate concession period becomes a complicated decision making activity among participants, and is under the influence of various economic and project factors, such as total investment, traffic flow, inflation rate (Ullah et al., 2016).
Generally, the optimization methods for the concession period can be divided into two categories, i.e. numerical simulation analysis methods (Carbonara et al., 2014; $\mathrm{Ng}$ et al., 2007; Zhang, 2009) and game analysis methods (Bao et al., 2015; Shen et al., 2005). Numerical simulation analysis is mainly used to describe the risks and uncertainties in the determination of the concession period ( $\mathrm{Ng}$ et al., 2007). The primary idea is to find the optimal length of the concession period under various risk circumstances (Shen \& Wu, 2005; Hanaoka \& Palapus, 2012). For example, Yu (2013) identified seven influential factors of the concession period, including toll fee, traffic flow, cost, inflation rate, etc., and proposed a decision-making support system using the Monte Carlo simulation method. Khanzadi (2013) used fuzzy numbers to describe the effects of different factors and employed dynamic simulation to determine the concession period at different confidence levels. One advantage of this method is that it can achieve the optimal concession period without the limitation of historical data (Ye \& Tiong, 2003). However, the interaction between main participants in the process is generally neglected.

Recently, studies have paid more attention to the negotiation and bargaining process between public and private sectors using the game theory (Bao et al., 2015; Scharle, 2002). Generally, the game theory can be employed to deal with the situations in which participants interact rationally with others (Akintoye et al., 2004). In a PPP-type 
contract, public and private sectors share the same project information and act with rationality in order to maximize their own benefits. Medda (2007) took the risk allocation between public and private sectors as a bargaining process, and introduced a final offer arbitration (FOA) game to solve the problem. Shen (2007) suggested that public and private sectors would bargain until them both realize their interests shall be no less than their basic expectations. Ho (2006) proposed a dynamic game-theory based model to describe the government's rescue behavior of distressed PPP projects.

To sum up, although a series of existing literature have studied the optimization of the concession period, there still exist some knowledge gaps which need to be filled. Firstly, most current studies focus on PPP projects that are fully financed by private sectors (Feng et al., 2017). However, with the increasing participation of public funds (in the form of subsidy or equity), it is highly necessary to consider the influence of public funds (Chen et al., 2012; Feng et al., 2017). Secondly, most previous research using game analysis is carried out from a static point of view, i.e. the time value of money is neglected. However, the construction and operation of PPP projects are usually over a time span of 20 to 30 years which can have strong influences on the calculation of fiscal indicators such as net present value (NPV) or internal rate of return (IRR) (Burger \& Hawkesworth, 2011).

This paper aims to fill the above gaps between previous research and current practice. The optimization of the concession period can be regarded as a gaming process between public and private sectors. This paper then used a combination of backward induction and numerical simulation to solve this problem. The influence of public equity and time value of money are also incorporated in the model. In Section 2, the problem background is clarified and basic assumptions are made. In Section 3, a mathematical model is constructed based on gaming analysis and discounted cash flow method (DCF), and is then solved using the classical backward induction method. In Section 4, a series of numerical simulations are carried out in order to validate the model and to demonstrate the influences of key impact factors. Finally, Section 5 summarizes and concludes the article.

\section{Problem Statement and Basic Assumptions}

In this project, the private sector is granted a fixed concession period by the public sector during which it will operate the project and collect user fees to recover initial investment and earn reasonable revenue. To encourage private sectors to actively participate in the project, public sectors have granted private sectors the right of determining an appropriate toll rate.

The decision making process of the concession period can then be regarded as a dynamic gaming process between public and private sectors. The public sector acts first to determine the length of the concession period. Based on this information, the private sector then chooses the appropriate toll rate in order to maximize its own economic profits. For ease of discussion, the following assumptions are made:

Assumption 1: The public sector plans to construct and operate a toll road through PPP mode. The project has a concession period of $T$ years and a design life of $\bar{T}$ years. The total investment of the project is $I$ and is invested at the time of $t=0$. The private sector recovers its investment through collecting user fees.

Assumption 2: To simplify the calculation, it is assumed that the project is built in an area with no other parallel roads and all vehicles are traveling at full speeds with no congestion problems. The traffic volume will not be affected by demographic, environment and force majeure. Under these conditions, the traffic volume is only affected by toll rates and service levels. In references to extant studies, the annual traffic flow of the project is set to be $Q_{P}=Q_{0} b^{-p / w}$, where $Q_{0}$ is the initial amount of traffic volume, $b$ is an integral determined by expert experience, $p$ is the price of toll rates, and finally $w$ represents the general level of service offered by project operators.

Assumption 3: The investment of construction cost $I$ is internal information of private sectors and is difficult to be observed by public sectors (Li et al., 2013). A short concession period may prompt private sectors to reduce their initial investment despite the fact that the maintenance cost may increase rapidly after the project is transferred back to public sectors in the future. The increase of construction cost I generally improves road quality and reduces the amount of operation and maintenance cost in the future. Thus, annual average maintenance cost for the project company is represented by $M_{I}=k_{1} k_{2} I^{-s}$, where $k_{1}$ and $k_{2}$ are two positive integers, and $s$ is an integer bigger than one. The above equation reflects the fact that initial increase in construction cost would help strengthen project quality and thus cut future maintenance cost.

Assumption 4: The discount rate for the project is set to be $r$. According to Taylor expansion of function $e^{x}, e^{r}$ equals to $(1+r)$ when $r$ is small enough. To simplify calculation, this model uses $e^{-r t}$ as an approximation of $(1+r)^{-t}$, representing the discount coefficient of year $t$ (Zhang \& Yang, 2015). Only the direct economic profits produced by the project are considered in this study, and social or non-economic profits are not considered.

\section{Decision Model of Concession Period}

For a PPP toll road characterized with the above assumptions, project revenue mainly comes from user fees. The equity share held by private sector is $\theta$, and the equity held by public sector is $(1-\theta)$. In this study, we use the economic profits received by public sectors as an approximation of public's social benefits. Public sectors' total economic profits can be divided into two parts according to their different time of acquirement.

The first part is economic profits created during the concession period and shared between public and private sectors. Its mathematical expression is represented by Equation (1) as shown below:

$$
(1-\theta) \int_{0}^{T}\left(P Q_{P}-M_{I}\right) e^{-r t} d t-(1-\theta) I
$$
where:

- $\theta$ is the percentage of equity held by private sectors.

- $T$ is the time length of the concession period.

- $P$ is the price of the toll rate.

- $Q_{P}$ is the annual traffic flow, $Q_{P}=Q_{0} b^{-p / w}$.

- $M_{I}$ is the annual operation cost.

- $\quad I$ is the total initial investment cost. 
Ke Feng, Shouqing Wang, Chunlin Wu, Guangtao Xia, Wangyin Hu. Optimization of Concession Period for Public...

The second part is the economic profits owned by public sectors alone after the project is turned over at the end of the concession period:

$$
\int_{T}^{\bar{T}}\left(P Q_{P}-M_{I}\right) e^{-r t} d t
$$

where $\bar{T}$ is the time length of design life.

By combining Equations (1) and (2), we can get the decision function for public sector as Equation (3):

$$
\begin{array}{r}
\text { Maxmize }\left[(1-\theta) \int_{0}^{T}\left(P Q_{P}-M_{I}\right) e^{-r t} d t-\right. \\
\left.(1-\theta) I+\int_{T}^{\bar{T}}\left(P Q_{P}-M_{I}\right) e^{-r t} d t\right]
\end{array}
$$

The decision variable for public sector is concession period $T$. Besides, private sectors will accept the project only when the profits they gained are equal to or larger than their reservation utility $\bar{\mu}$, i.e. the minimum level of utility private sector would get if no contract is written. Thus, the participation constraints for private sector can be represented as Equation (4) below:

$$
\theta \int_{0}^{T}\left(P Q_{P}-M_{I}\right) e^{-r t} d t-\theta I \geq \bar{\mu}
$$

When public and private sectors have signed a concession contract, both of them made relative decisions in order to maximize their own interests. They make decisions in a chronological order. Firstly, the government maximizes its interests by choosing the appropriate concession period $T$. Then, in reference to this concession period, the private sector then decides the appropriate toll rate $P$ it needs to charge. The decision model for private sectors is listed by Equation (5) below. Its decision variable is $P$.

$$
\text { Maxmize }\left[\theta \int_{0}^{T}\left(P Q_{P}-M_{I}\right) e^{-r t} d t-\theta I\right]
$$

\section{Solving Sub-game Perfection Using Backward Induction}

Backward induction is one of the most common algorithms for extensive gaming problems. This procedure starts at the end of the game tree and works back up to solve for optimal behavior at each node (Aumann, 1995). This paper has employed this method to solve the sub-game perfection in the above mentioned gaming problem. The decision model for private sector can be transformed into Equation (6) after putting the value of parameters into Equation (5).

Maximize $\left[\theta \int_{0}^{T}\left(P Q_{0} b^{-\frac{p}{w}} d t-k_{1} k_{2} I^{-s} e^{-r t}\right) d t-\theta I\right]$

The optimal toll rate $P^{*}$ chosen by private sectors can be calculated after the concession period has been determined as $T$. In order to find the critical point of Equation (6), we need to calculate the first derivative of the above function. The calculation result is shown in Equation (7).

$$
P^{*}=w
$$

It can be seen that under such circumstances, the optimal toll rate $P^{*}$ shall be determined based on the average level of service that the private sector can offer to customers and is not influenced by the length of the concession period.

When the public sector predicts that the private sector would set the optimal toll rate to be $P^{*}$, the decision model and constraints for the public sector are then transformed into Equation (8) and Equation (9).

$$
\begin{aligned}
& \text { Maximize }\left[(1-\theta) \int_{0}^{T}\left(P^{*} Q_{P^{*}}-M_{I}\right) e^{-r t} d t-(1-\theta) I+\right. \\
& \left.\qquad \int_{T}^{\bar{T}}\left(P^{*} Q_{P^{*}}-M_{I}\right) e^{-r t} d t\right] \\
& \text { Subject to : } \theta \int_{0}^{T}\left(P^{*} Q_{P^{*}}-M_{I}\right) e^{-r t} d t-\theta I \geq \bar{\mu}
\end{aligned}
$$

To solve the above optimization problems, we have employed the Lagrangian function method to incorporate Equation (9) into the objective function. When the concession period $T$ is optimized, Equation (9) will become an equation instead. In other words, an optimized concession period shall be long enough to guarantee that private sectors can earn a profit equal to its reservation utility yet not too long to make it gain an extra profit (Gross \& Garvin, 2009). Thus, by using Lagrangian function method, Equations (8) and (9) are transformed into Equation (10):

$$
\begin{aligned}
& \mathrm{L}=(1-\theta) \int_{0}^{T}\left(P^{*} Q_{P^{*}}-M_{I}\right) e^{-r t} d t-(1-\theta) I+ \\
& \int_{T}^{\bar{T}}\left(P^{*} Q_{P^{*}}-M_{I}\right) e^{-r t} d t+\lambda\left[\theta \int_{0}^{T}\left(P^{*} Q_{P^{*}}-M_{I}\right) e^{-r t} d t-\theta I-\right. \\
& \bar{\mu}]
\end{aligned}
$$

where $\lambda$ is the Lagrangian multiplier. The first order optimization condition for Equation (10) is listed below:

$$
\frac{\partial L}{\partial \lambda}=\theta \int_{0}^{T}\left(P^{*} Q_{P^{*}}-M_{I}\right) e^{-r t} d t-\theta I-\bar{\mu}=0
$$

Equation (11) can be further simplified as listed below:

$$
\theta P^{*} Q_{p^{*}}\left(\frac{1-e^{-r T^{*}}}{r}\right)-\theta k_{1} k_{2} I^{-s}\left(\frac{e^{r T^{*}}-1}{r}\right)-\theta I-\bar{\mu}=0
$$

Through sorting Equation (12), the optimal concession period $T^{*}$ can be calculated. However, there are numerous parameters in the above equation and the expression is complex and nonlinear which makes it difficult to get an analytic solution. The following section will use numeric simulation methods to get a numerical solution for the optimized concession period $T^{*}$, and also to explore the influences of different factors on it.

\section{Numerical Simulation for Optimal Concession Period}

In this section, numerical simulations are carried out to derive the optimal concession period under various circumstances. The model input parameters are listed in Table 1.

Table 1

Basic Values for Input Variables

\begin{tabular}{|c|c|c|c|}
\hline Variables & Definitions & Units & Values \\
\hline$Q_{0}$ & $\begin{array}{c}\text { initial traffic } \\
\text { volume }\end{array}$ & $\begin{array}{c}\text { million per } \\
\text { year }\end{array}$ & 4.5 \\
\hline$b$ & integer & not applicable & 0.5 \\
\hline$P^{*}$ & toll rate & yuan per car & 20 \\
\hline$r$ & risk-free rate & $\begin{array}{c}\text { hundred } \\
\text { percent }\end{array}$ & $4.9 \%$ \\
\hline$\theta$ & private equity ratio & $\begin{array}{c}\text { hundred } \\
\text { percent }\end{array}$ & $>50 \%$ \\
\hline$I$ & initial investment & million yuan & 1200 \\
\hline $\bar{\mu}$ & opportunity cost & million yuan & 750 \\
\hline$k_{1}$ & integer & not applicable & 20 \\
\hline$k_{2}$ & integer & not applicable & 15 \\
\hline $\mathrm{s}$ & integer & not applicable & 1.2 \\
\hline
\end{tabular}


Reasons for their values are discussed below.

Firstly, when the concession period is optimized, the optimal toll rate $P^{*}$ shall equal to average service level $w$ according to Equation (7). The annual traffic volume at $P^{*}$ is only affected by the value of initial traffic volume $Q_{0}$ and integer $b$. In the above Table, values of $Q_{0}, b$ and $P^{*}$ are all determined based on similar PPP toll road projects in China. Under these conditions, the annual traffic volume $Q^{*}$ is calculated to be 7.5 million cars.

Secondly, in China, the current bank debt rate of longterm commercial loans for a period of over 5 years is stipulated to be $4.9 \%$, which can be used as an approximation for long-term risk free rate $r$.

Thirdly, according to China's relative regulations, the public sector can only act as a minority shareholder in a PPP project $(\mathrm{Ji}, 2016)$. In other words, the private sector should hold equity bigger than $50 \%$, which can be the lower limit of this factor. Thus, we used this value as the bottom value of private equity ratio $\theta$ in the simulation.

Fourthly, values of $I$ and $\bar{\mu}$ are determined in reference to similar projects and expert opinions. Finally, values of $k_{1}, \mathrm{k}_{2}$ and $\mathrm{s}$ are determined in reference to extant studies made by Yang et al. (2003).

For a PPP toll road with initial investment of 1.2 billion yuan, with parameters listed in the above Table 1, we can get the initial optimization result for the concession period to be 21.66 years. This result is normal compared to similar projects, proving the applicability of the proposed model.

Further, this model has selected five parameters, including $\mathrm{r}, P^{*}, I, \theta$ and $\bar{\mu}$, to study their potential influences on the optimization of the concession period. The variation range of each parameter is divided into equidistant $\mathrm{N}$ sections with $(\mathrm{N}+1)$ points. Then the corresponding optimal concession period is calculated by introducing those newly generated points into Equation (12).

(1) Risk free interest rate $r$

In order to illustrate the impacts of risk free interest rate on the optimal concession period, we have set the range of risk-free interest rate $r$ to be $[3.92 \%, 5.88 \%$ ], i.e. $20 \%$ variation of the base interest rate of $4.9 \%$. In this variation range, the interest rate would change at $0.196 \%$, dividing the whole space into 100 equal parts. The curve of the optimal concession period is shown in Figure 1.

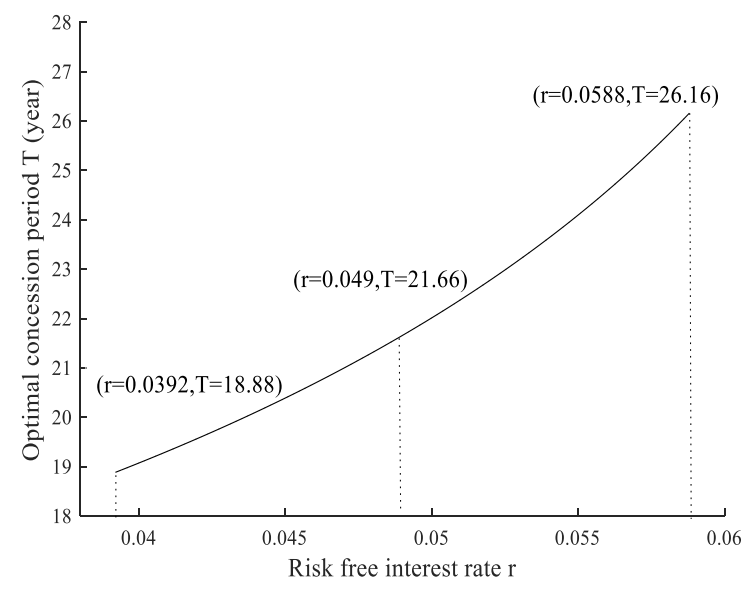

Figure 1. Impact of Risk Free Interest Rate on Optimal Concession Period
Figure 1 shows that the optimal concession period $T$ is positively correlated with the risk free interest rate $r$. Yet, they are not linearly related, as can be seen from the gradually increasing slope of the curve. When the risk free interest rate $r$ varies from $3.92 \%$ to $5.88 \%$, the optimal concession period increases from 18.88 years to 26.16 years.

Reasons for this positive correlations may be that the discount rate of the project also increases with the uprise of risk free interest rate. As a result, the private sector needs to spend more in order to get enough financing for the project, which demands the concession period to be extended in order to make the project more profitable and break-even.

(2) Toll rate $P$

To examine the influences of the toll rate on the optimal concession period, the range of toll rate is set to be [16, 24], which varies $20 \%$ around the basic value of 20 yuan. And it varies by 0.08 yuan at a time. The curve of the optimal concession period is shown in Figure 2 below.

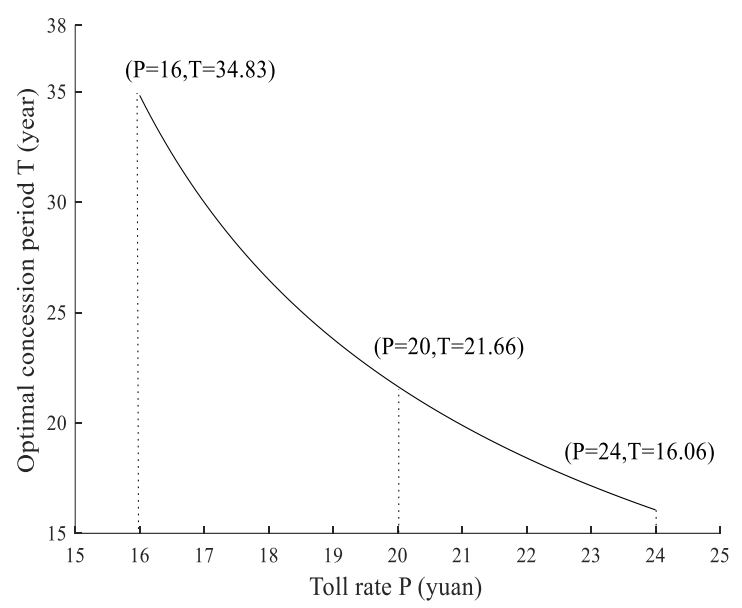

Figure 2. Impact of Toll Rate on Optimal Concession Period

$$
\text { Source: Own elaboration }
$$

The influence of toll rate $P$ on optimal concession period $T$ is complicated. On one hand, by increasing the toll rate, it becomes easier for private sectors to collect economic revenue, which means they can probably achieve the same profit in a shorter concession period. As can be seen in Figure 2, the optimal concession period decreases from 34.83 years to 16.06 years as the toll rate increases from 16 yuan per car to 24 yuan per car.

On the other hand, the traffic flow will be suppressed with the increase of the toll rate. Fewer drivers would choose to use the lanes if the toll rate has been raised to higher levels (Lou et al., 2011). Thus, as the toll rate increases, the total traffic flow will decrease. Under the combined action of these two forces (i.e. increasing toll rates and decreasing traffic flows), the optimal concession period decreases in a reducing speed as reflected in Figure 2.

When the toll rate increases from 16 yuan to 20 yuan, the optimal concession period decreases from 34.83 years to 21.66 years, representing an average decreasing rate of 3.29 years per yuan. However, when the toll rate further climbs from 20 yuan to 24 yuan, the optimal concession period changes from 21.66 years to 16.06 years, representing an average decreasing rate of 1.4 years per yuan. Obviously, the 
Ke Feng, Shouqing Wang, Chunlin Wu, Guangtao Xia, Wangyin Hu. Optimization of Concession Period for Public...

reduction of the optimal concession period caused by price growth has weakened gradually.

(3) Initial Investment $I$

In order to investigate the impacts of initial investment on optimal concession period $T$, the variation range of initial investment is set to be $[960,1440]$ and changes at 3.2 million yuan per time. The curve of the optimal concession period is shown in Figure 3 below.

Generally speaking, optimal concession period grows gradually with the increase of initial investment. Reason for this phenomena is that private sectors need to expand the optimal concession period in order to recover the extra costs caused by the increase of initial investments.

It should be noted that the curve is not a linear increase curve. Its slope is actually slowly growing with the increase of initial investment $I$. This can be proved by calculating the slopes of the first and second half of the curve.

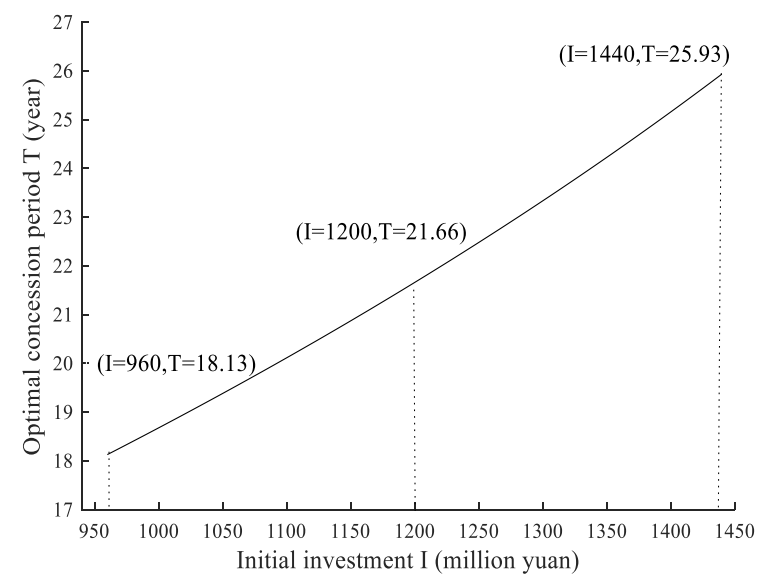

Figure 3. Impact of Initial Investment on Optimal Concession Period

Source: Own elaboration

When the initial investment increases from 0.96 billion yuan to 1.2 billion yuan, the optimal concession period increases from 18.13 years to 21.66 years, representing an average increase rate of 14.70 years per billion yuan. For the second half of the curve, the initial investment increases from 1.2 billion yuan to 1.44 billion yuan, the optimal concession period increases from 21.66 years to 25.93 years, representing an average increase rate of 17.79 years per billion yuan.

The following is a brief explanation for this phenomenon. As discussed in Assumption 3, the increase of initial investment usually comes with improvement in the quality of toll road projects, which further leads to the decrease of operation and maintenance cost $M_{I}$. However, this savings of $M_{I}$ are not linear and are actually diminishing with the increase of $I$. This can be seen from $M_{I}=k_{1} k_{2} I^{-s}$, where $s$ is an positive integer bigger than one. Since the operation and maintenance cost $M_{I}$ reduces in a decreasing speed, the optimal concession period would have to grow with a slightly increasing speed in order to compensate for the increase in initial investment.

(4) Private Equity Ratio $\theta$

As discussed in Table 1, the bottom value for the private equity ratio is set to be $50 \%$. To be in consistent with previous analysis, the variation range of private equity ratios is set to be $[0.5,0.75]$, which marks a $20 \%$ increase or decrease at the basic value of 0.625 . And it changes at 0.0025 per time.

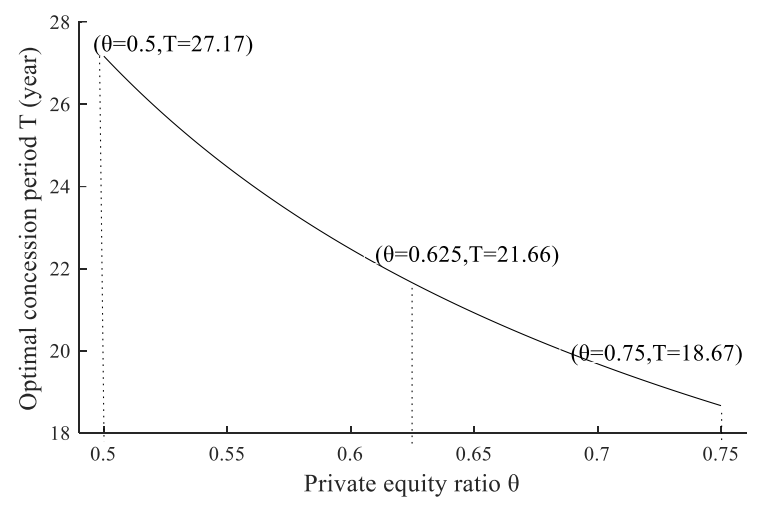

Figure 4. Impact of Private Equity Ratio on Optimal Concession Period

Source: Own elaboration

Generally speaking, the optimal concession period decreases with the increase of private equity ratio. Even though the private sector needs to take more financing, the relative pro rata dividends also increase with the rising of equity ratio. Obviously, in this project, the influence of increase in prorated dividends has surpassed increase of equity investment and became a dominant force. Thus, the optimal concession period shall be shortened since more economic gains are reaped every year when the private equity ratio increases.

The optimal concession period decreases in a diminishing speed. When the private equity ratio increases from $50 \%$ to $62.5 \%$, optimal concession period decreases from 27.17 years to 21.66 years, representing a decreasing speed of 4.41 years per 10 percent. When the private equity ratio further increases from $62.5 \%$ to $75 \%$, optimal concession period decreases from 21.66 years to 18.67 years, representing a decreasing speed of 2.39 years per 10 percent.

(5) Reservation Utility $\bar{\mu}$

To examine the effects of reservation utility on the optimal concession period, the range of reservation utility is set to be $[100,500]$ and varies by 10 million yuan at a time.

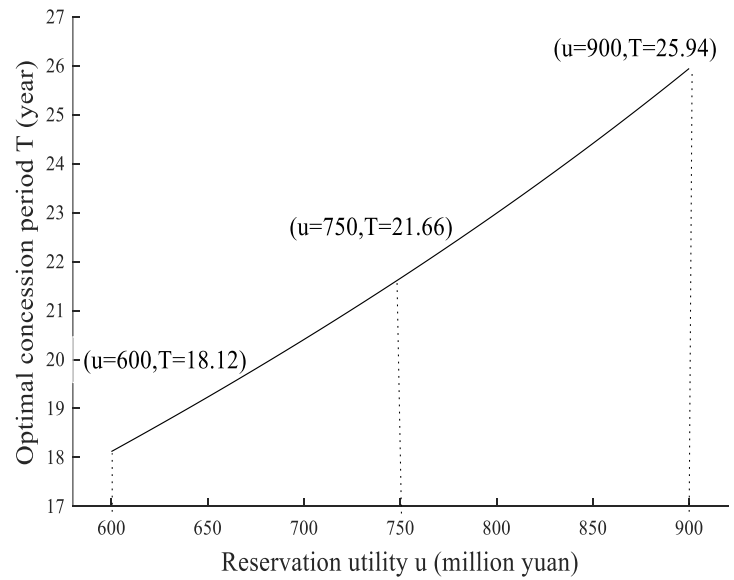

Figure 5: Impact of reservation utility on optimal concession period

Source: Own elaboration 
As can be seen from Figure 5, the optimal concession period generally increases with the growth of reservation utility of private sector. As discussed in Equation (9), private sector chooses to participate in the PPP toll road project only when the economic gain it gets is no less than the reservation utility it can achieve by taking advantages of other investment opportunities. Thus, with the increase of reservation utility, the optimal concession period needs to be lengthened in order to keep the project financially attractive to private sectors.

This curve is also not linearly increasing. When the reservation utility increases from 0.6 billion to 0.75 billion, the optimal concession period increases from 18.12 years to 21.66 years, representing an average increase speed of 2.36 years per 0.1 billion. When the reservation utility increased from 0.75 billion to 0.9 billion, the optimal concession period increases from 21.66 years to 25.94 years, representing an average increase speed of 2.85 years per 0.1 billion.

\section{Discussion}

This study aims to explore the optimization of the concession period, which is an important issue for the successful implementation of PPP toll roads. While several previous research works are related to this topic, they are generally limited for the neglecting of public equity and time value of money.

The main contribution of this paper is the detailed introduction of a gaming model which can be applied to determine the optimal concession period that satisfies both participants. This new model has been solved using backward induction methods. Also, a series of numerical simulations are applied in order to show the influences of different factors, such as risk free interest rates, toll rates, initial investments, etc.

This approach is an extension to the traditional studies using game theory. The influences of public equity and time value of money are incorporated into the model. Rather than offering an analytical solution, the proposed model offers a very complex numerical solution. To explore its properties, we have used a series of numerical simulations which have virtually shown the changes of optimal concession period in a variety of different circumstances.

Nevertheless, this study also bears several limitations as follows:

\section{Acknowledgements}

This study is financially supported by the National Natural Science Foundation of China (Project Nos. 71772098 and 71801007), and MOE (Ministry of Education in China) Project of Humanities and Social Sciences (No. 18YJCZH188).

\section{References}

Akintoye, A., Hardcastle, C., \& Chinyio, E. (2004). Application of game theory in Public Private Partnerships. In Project Procurement for Infrastructure Construction. Proceedings of the CIB W092 Procurement Systems Symposium, January (pp. 7-10).

Aumann, R. J. (1995). Backward induction and common knowledge of rationality. Games and Economic Behavior, 8(1),
- This model uses the economic gains of public sectors as an approximation of public interests and the model is generally built from an economic or financial perspective. This approach has made it easier to quantify relative factors and construct the model. However, the determination of the concession period may be influenced by other non-economic or political factors in real life (Tiong, 1990).

- The effective application of the model depends on the necessary information of the project, such as factors' initial values and their variation ranges. These values may not be readily available or might be predicted in an inappropriate way, which may have a potentially negative impact on the model outputs. To solve this problem, project participants should address efforts to the precise predictions of future forecasts.

Notably, this paper by no means intends to cover the optimization of the concession period in its entirety, but rather to provide instructions for public and private sectors on this issue. As a line of future research, there are also several interesting directions that can be explored in this area such as the variations of the optimal concession period when multi-factors are changing simultaneously or when the model's initial assumptions have been further relaxed.

\section{Conclusions}

By combining the financing characteristics of PPP modes and the operation characteristics of toll roads, this paper has established a mathematical gaming model that satisfies the respective interests of public and private sectors. The method of backward induction is used to solve the model and numerical simulation is conducted to draw the following several major conclusions. Firstly, the optimal toll rate should be determined in reference to the average level of services provided by the private sector. Secondly, the risk free interest rate, initial investment and reservation utility are factors positively correlated with the optimal concession period. And the optimal concession period grows with a slightly increasing speed with the increment of those above mentioned factors. Thirdly, the toll rate and the private equity ratio are negatively correlated with the optimal concession period. The optimal concession period declines with a decreasing speed with the increment of the toll rate.

The mathematical gaming model developed in the current paper can effectively identify the optimal concession period for a PPP toll road. The results can also provide useful guidance for public and private sectors of PPP projects in negotiations on related issues.

\footnotetext{
6-19. https://doi.org/10.1016/S0899-8256(05)80015-6
} 
Ke Feng, Shouqing Wang, Chunlin Wu, Guangtao Xia, Wangyin Hu. Optimization of Concession Period for Public ...

Bao, H., Peng, Y., Ablanedo-Rosas, J. H., \& Gao, H. (2015). An alternative incomplete information bargaining model for identifying the reasonable concession period of a BOT project. International Journal of Project Management, 33(5), 1151-1159. https://doi.org/10.1016/j.ijproman.2014.12.004

Burger, P., \& Hawkesworth, I. (2011). How to attain value for money: comparing PPP and traditional infrastructure public procurement. OECD Journal on Budgeting, 11(1), 1-56. https://doi.org/10.1787/budget-11-5kg9zc0pvq6j

Carbonara, N., Costantino, N., \& Pellegrino, R. (2014). Concession period for PPPs: A win-win model for a fair risk sharing. International Journal of Project Management, 32(7), 1223-1232. https://doi.org/10.1016/j.ijproman. 2014.01.007

Chen, B., Liou, F. M., \& Huang, C. P. (2012). Optimal financing mix of financially non-viable private-participation investment project with initial subsidy. Inzinerine Ekonomika-Engineering Economics, 23(5), $452-461$. https://doi.org/10.5755/j01.ee.23.5.3130

Feng, K., Xiong, W., Wang, S., Wu, C., \& Xue, Y. (2017). Optimizing an Equity Capital Structure Model for Public-Private Partnership Projects Involved with Public Funds. Journal of Construction Engineering and Management, 143(9), 04017067. https://doi.org/10.1061/(ASCE)CO.1943-7862.0001349

Gross, M. E., \& Garvin, M. J. (2009). Approaches for structuring concession lengths and toll rates for transportation infrastructure PPPs. In Construction Research Congress 2009: Building a Sustainable Future (pp. 191-200). https://doi.org/10.1061/41020(339)20

Feng, K., Wang, S., \& Xue Y. (2017). Optimization of PPP project equity structures based on the satisfactions of the main stakeholders. Journal of Tsinghua University (Science and Technology), 57(4), 376-381.

Hanaoka, S., \& Palapus, H. P. (2012). Reasonable concession period for build-operate-transfer road projects in the Philippines. International Journal of Project Management, 30(8), 938-949. https://doi.org/10.1016/j.ijproman. 2012.02.001

Ho, S. P. (2006). Model for financial renegotiation in public-private partnership projects and its policy implications: Game theoretic view. Journal of Construction Engineering and Management, 132(7), 678-688. https://doi.org/10.1061/ (ASCE)0733-9364(2006)132:7(678)

Kappeler, A., \& Nemoz, M. (2010). Public-Private Partnerships in Europe-before and during the recent financial crisis (No. 2010/04). Economic and financial reports/European Investment Bank.

Ke, Y., Wang, S., Chan, A. P., \& Lam, P. T. (2010). Preferred risk allocation in China's public-private partnership (PPP) projects. International Journal of Project Management, 28(5), 482-492. https://doi.org/10.1016/j.ijproman. 2009.08.007

Khanzadi, M., Nasirzadeh, F., \& Alipour, M. (2012). Integrating system dynamics and fuzzy logic modeling to determine concession period in BOT projects. Automation in construction, 22, 368-376. https://doi.org/10.1016/j.autcon. 2011.09.015

Li, L., Liu, Z. H., \& Zhang, K. C. (2013). Game model for PPP project's risk allocation under the asymmetry condition of participant's position. Systems Engineering Theory and Practice, 33(8), 1940-1948.

Jasiukevicius, L., \& Vasiliauskaite, A. (2018). The Assessment of Public-Private Partnership's Possibilities to Optimize Investments in Public Infrastructure. Inzinerine Ekonomika-Engineering Economics, 29(1), 32-45. https://doi.org/10. 5755/j01.ee.29.1.19101

Lou, Y., Yin, Y., \& Laval, J. A. (2011). Optimal dynamic pricing strategies for high-occupancy/toll lanes. Transportation Research Part C: Emerging Technologies, 19(1), 64-74. https://doi.org/10.1016/j.trc.2010.03.008

Medda, F. (2007). A game theory approach for the allocation of risks in transport public private partnerships. International Journal of Project Management, 25(3), 213-218. https://doi.org/10.1016/j.ijproman.2006.06.003

Ng, S. T., Xie, J., Cheung, Y. K., \& Jefferies, M. (2007). A simulation model for optimizing the concession period of publicprivate partnerships schemes. International Journal of Project Management, 25(8), 791-798. https://doi.org/10.10 16/j.ijproman.2007.05.004

Ng, S. T., Xie, J., Skitmore, M., \& Cheung, Y. K. (2007). A fuzzy simulation model for evaluating the concession items of public-private partnership schemes. Automation in construction, 17(1), 22-29. https://doi.org/10.1016/j.autcon. 2007.02.010

Osborne, S. (2002). Public-private partnerships: Theory and practice in international perspective. Routledge, Taylor \& Francis Group Ltd., Abingdon Oxford, UK. https://doi.org/10.4324/9780203207116

Scharle, P. (2002). Public-private partnership (PPP) as a social game. Innovation: The European Journal of Social Science Research, 15(3), 227-252. https://doi.org/10.1080/1351161022000027630

Shen, L. Y., Bao, H. J., Wu, Y. Z., \& Lu, W. S. (2007). Using bargaining-game theory for negotiating concession period for BOT-type contract. Journal of Construction Engineering and Management, 133(5), 385-392. https://doi.org/10. 1061/(ASCE)0733-9364(2007)133:5(385) 
Shen, L. Y., Li, H., \& Li, Q. M. (2002). Alternative concession model for build operate transfer contract projects. Journal of Construction Engineering and Management, 128(4), 326-330. https://doi.org/10.1061/(ASCE)0733-9364(20 02)128:4(326)

Shen, L. Y., \& Wu, Y. Z. (2005). Risk concession model for build/operate/transfer contract projects. Journal of Construction Engineering and Management, 131(2), 211-220. https://doi.org/10.1061/(ASCE)0733-9364 (2005)131:2(211)

Skietrys, E., Raipa, A., \& Bartkus, E. V. (2008). Dimensions of the efficiency of public-private partnership. Inzinerine Ekonomika-Engineering Economics, 58(3), 45-50.

Sun, H., Fan, Z. Q., \& Shi, Y. (2011). Research on the optimal ownership structure of an expressway under a PPP scheme. Journal of Industrial Engineering/Engineering Management, 1, 154-157.

Tang, L., Shen, Q., \& Cheng, E. W. (2010). A review of studies on public-private partnership projects in the construction industry. International Journal of Project Management, 28(7), 683-694. https://doi.org/10.1016/j.ijproman. 2009.11.009

Tiong, R. L. (1990). BOT projects: Risks and securities. Construction Management and Economics, 8(3), $315-328$. https://doi.org/10.1080/01446199000000026

Ullah, F., Ayub, B., Siddiqui, S. Q., \& Thaheem, M. J. (2016). A review of public-private partnership: critical factors of concession period. Journal of Financial Management of Property and Construction, 21(3), $269-300$. https://doi.org/10.1108/JFMPC-02-2016-0011

Wang, D. B., Song, J. B., Dai, D. S., \& Li, Z. (2011). Decision-Making on Concession Period for Traffic BOT Project under Elastic Demand. Journal of Industrial Engineering and Engineering Management, 3, 019.

Ji, X., Shanghai Municipal Finance Bureau (2016). Analysis of Realistic Foundations for Solving PPP Financing Difficulties and Countermeasures. Available from Internet: http://www.cpppc.org/en/DomesticKnowledge/ 4710.jhtml.

Yang, H., Zhou, J., \& He, J. (2003). Decision-Making Model on Concession Term for Traffic BOT Project on the Basis of Game Theory. Journal of Industrial Engineering Management. 17(3), 93-95.

Ye, S., \& Tiong, R. L. (2003). The effect of concession period design on completion risk management of BOT projects. Construction Management and Economics, 21(5), 471-482. https://doi.org/10.1080/0144619032000073488

Yu, C. Y., \& Lam, K. C. (2013). A Decision Support System for the determination of concession period length in transportation project under BOT contract. Automation in Construction, 31, 114-127. https://doi.org/10.1016/j. autcon.2012.11.012

Zhang, H., \& Yang, F. (2015). Optimization of Capital Structure in Real Estate Enterprises. Journal of Industrial and Management Optimization, 11(3), 969-983. https://doi.org/10.3934/jimo.2015.11.969

Zhang, X. (2009). Win-win concession period determination methodology. Journal of Construction Engineering and Management, 135(6), 550-558. https://doi.org/10.1061/(ASCE)CO.1943-7862.0000012

Zhang, X., \& AbouRizk, S. M. (2006). Determining a reasonable concession period for private sector provision of public works and service. Canadian Journal of Civil Engineering, 33(5), 622-631. https://doi.org/10.1139/106-010

The article has been reviewed.

Received in October 2017; accepted in February 2019. 